Pacific Journal of Mathematic 


\title{
ON THE CHOQUET BOUNDARY FOR A NONCLOSED SUBSPACE OF $C(S)$
}

\section{TAE-Guen Cho}

\begin{abstract}
In this paper, it is proved that if a separating (not necessarily closed) subspace $X$ of $C(S)$ which contains all the constant functions is generated by a weakly compact convex subset, then the peak points for $X$ are dense in the Choquet boundary for $X$. In order to prove the theorem the extremal structure of convex subsets of the conjugate space of a normed linear space is studied.
\end{abstract}

Let $S$ be a compact Hausdorff space, $C(S)$ the Banach space of all continuous complex functions on $S$ with the sup norm and let $X$ denote a separating subspace of $C(S)$ which contains all the constant functions. $X$ need not be closed under the sup norm. If $X$ is a closed sub-algebra of $C(S)$ and $S$ is metrizable, then the Choquet boundary for $X$ is exactly the set of peak points for $X$, [cf. 2]. If $X$ is not an algebra, this conclusion may fail to hold. However, if $X$ is closed and separable, then the peak points for $X$ are dense in the Choquet boundary for $X$ (cf. [5]). In this paper the latter will be generalized for certain nonclosed subspaces of $C(S)$. In $\S 2$, it will be shown that if a subspace $X$ is generated by a weakly compact convex subset than the set $M=\left\{x^{*} \in X^{*} ; x^{*}(1)=1=\left\|x^{*}\right\|\right\}$ is the weak* closed convex hull of its weak* absolute exposed points (see Definition 2.3 in $\S 2$ for absolute exposed points). In $\S 3$ it will be proved that a functional $x^{*}$ in $M$ is a weak* absolute exposed point of $M$ if and only if there is a peak point $s \in S$ for $X$ such that $x^{*}=\dot{\phi}(s)$ where $\phi$ is the natural embedding of $S$ into $X^{*}$. The main theorem is a simple consequence of the above two theorems.

2. Normed linear spaces generated by weakly compact convex subsets. Let $K$ be a weakly compact subset of a normed linear space $Y$. If the linear span of $K$ is norm dense in $Y$, then $Y$ is said to be generated by a weakly compact subset $K$. The set $K$ is called a fundamental subset of $Y$. In a Banach space, the closed convex hull of a weakly compact subset is weakly compact, and hence a Banach space is generated by a weakly compact convex subset if it is generated by a weakly compact subset. But there is an incomplete normed linear space generated by a weakly compact subset which does not contain a weakly compact convex fundamental subset (see Example 3 in $\S 3$ ). It is clear that every separable normed linear space is generated by a weakly compact subset. Therefore, every 
norm bounded linear image of a separable Banach space is generated by a weakly compact convex subset.

Let $F$ be a subspace of the conjugate space $Y^{*}$ of a normed linear space $Y$.

Definition 2.1. A point $x$ of a convex subset $C$ of $Y$ is an $F$ exposed point of $C$ if there exists a functional $f$ in $F$ such that $\operatorname{Re} f(x)>\operatorname{Re} f(y)$ for all $y \in C, y \neq x$.

If $F$ coincides with the conjugate space $Y^{*}$, then an $F$-exposed point is called an exposed point. If $Y$ is a conjugate space of a normed linear space and $F$ is the set of all weak* continuous functionals on $Y$, then an $F$-exposed point is called a weak* exposed point. General information about exposed points can be found in either [3] or [4].

Our first theorem is an easy consequence of methods used by Amir and Lindenstrauss in proving a related result, Theorem 4 of [1].

THEOREM 2.2. Let $Y$ be a normed linear space generated by a weakly compact convex subset. Then every weak* compact convex subset $C$ of the conjugate space $Y^{*}$ is the weak* closed convex hull of its weak* exposed points.

Proof. It is clear from the proof of Proposition 2 of [1] that the latter is valid for an incomplete space if it is generated by a weakly compact convex set. The reasoning of Theorem 4 of [1] applies to yield the desired conclusion.

DEFINITION 2.3. A point $x$ of a convex subset $C$ of a normed linear space $Y$ is an (weak*) absolute exposed point of $C$ if there is a (weak*) continuous linear functional $f$ such that

$$
f(x)=\sup \{|f(y)|: y \in C\} \text { and } f(x) \neq \operatorname{Re} f(y) \text { for all } y \in C, y \neq x .
$$

If $x$ is an absolute exposed point of a convex set $C$ and if $f$ is a functional which realizes its maximum modulus over $C$ at $x$ then the affine functional $f+1$ peaks at $x$. An absolute exposed point is an exposed point but the converse does not hold, (see Example 1 in $\S 3$ ). However, it is clear from the definition that every exposed point of a circled convex set is an absolute exposed point of the set.

LEMma 2.4. Suppose that $z=\sum_{j=1}^{n} t_{j} \alpha_{j}$, where $\left|a_{j}\right| \leqq 1$ and $t_{j}>0$ for each $j$ and $\sum_{j=1}^{n} t_{j}=1$. If $\operatorname{Re} z>\sqrt{1-\delta^{2}}$ for a given $0<\delta<1$, then $\sum_{j=1}^{n} t_{j}\left|\operatorname{Im} \alpha_{j}\right|<\delta$. 
Proof. Let $z_{1}=\sum_{j=1}^{n} t_{j}\left(\operatorname{Re} \alpha_{j}+i\left|\operatorname{Im} \alpha_{j}\right|\right) . \quad$ Then $\operatorname{Re} z=\operatorname{Re} z_{1}$ and $\left|z_{1}\right| \leqq 1$. Now

$$
\left(\sum_{j=1}^{n} t_{j}\left|\operatorname{Im} \alpha_{j}\right|\right)^{2}=\left(\operatorname{Im} z_{1}\right)^{2}=\left|z_{1}\right|^{2}-\left(\operatorname{Re} z_{1}\right)^{2}<1-\left(1-\delta^{2}\right)=\delta^{2} .
$$

THEOREM 2.5. Let $X$ be a separating subspace of $C(S)$ with $1 \in X$. If $X$ is generated by a weakly compact convex subset, then $M=\left\{x^{*} \in X^{*} ; x^{*}(1)=1=\left\|x^{*}\right\|\right\}$ is the weak* closed convex hull of its weak* absolute exposed points.

Proof. Let $M_{1}$ be the weak* closed convex hull of

$$
M_{0}=\left\{\alpha x^{*} ; \alpha=\alpha+i b \text { with }|\alpha| \leqq 1 \text { and } x^{*} \in M\right\} .
$$

Since $M_{1}$ is a circled weak* compact convex set, it is the weak* closed convex hull of its weak* absolute exposed points by Theorem 2.2. Let $C$ be the weak* closed convex hull of all the weak* absolute exposed points of $M_{1}$ which are in $M$. It suffices to show that $C=M$. Suppose that $C \neq M$ and let $z^{*}$ be a functional in $M-C$. By the separation theorem, we may choose a function $z$ in $X$ with $\|\boldsymbol{z}\|=1$ and a number $\delta, 0<\delta<1$, such that

$$
\operatorname{Re} z^{*}(z)>2 \delta+\sup \left\{\operatorname{Re} x^{*}(z) ; x^{*} \in C\right\} \text {. }
$$

Since $x^{*}(1)=1$ for all $x^{*}$ in $M$ we may assume that $\operatorname{Re} x^{*}(z) \geqq 0$ for all $x^{*}$ in $M$. On the other hand, since the functional $z^{*}$ is in $M_{1}$, the weak* closed convex hull of weak* absolute exposed points of itself, for the number $\delta$ we may choose a functional

$$
y^{*}=\sum_{i=1}^{n} t_{i} y_{i}^{*}
$$

where $\sum_{i=1}^{n} t_{i}=1,0<t_{i}<1$ and $y_{i}^{*}$ is a weak $*$ absolute exposed point of $M_{1}, i=1,2, \cdots, n$, such that

$$
\left|z^{*}(z)-y^{*}(z)\right|<\delta
$$

and

$$
\left|z^{*}(1)-y^{*}(1)\right|<1-\sqrt{1-\delta^{2}}
$$

Note that $y_{i}^{*}=\alpha_{i} z_{i}^{*}$, where $\alpha_{i}$ is a complex number with $\left|\alpha_{i}\right| \leqq 1$ and $z_{i}^{*}$ is a function in $M$ which is a weak* absolute exposed point of $M_{1}$, since every exposed point of $M_{1}$ belongs to $M_{0}$ by Milman's theorem. Therefore,

$$
y^{*}=\sum_{i=1}^{n}\left(t_{i} \alpha_{i}\right) z_{i}^{*}
$$


Since $z^{*}, z_{i}^{*} \in M, z^{*}(1)=1$ and $z_{i}^{*}(1)=1$, hence, taking the real part of $z^{*}(1)-y^{*}(1)$ of (2) we see that $\operatorname{Re} y^{*}(1)>\sqrt{1-\delta^{2}}$. Therefore, $\sum_{i=1}^{n} t_{i}\left|\operatorname{Im} \alpha_{i}\right|<\delta$ by the lemma.

Now,

$$
\begin{aligned}
\left|z^{*}(z)-y^{*}(z)\right| & \geqq\left|\operatorname{Re} z^{*}(z)-\operatorname{Re} y^{*}(z)\right| \\
& =\mid \sum_{i=1}^{n} t_{i}\left[\operatorname{Re} z^{*}(z)-\left(\operatorname{Re} \alpha_{i}\right)\left(\operatorname{Re} z_{i}^{*}(z)\right)\right] \\
& +\sum_{i=1}^{n} t_{i}\left(\operatorname{Im} \alpha_{i}\right)\left(\operatorname{Im} z_{i}^{*}(z)\right) \mid \\
& \geqq 2 \delta-\sum_{i=1}^{n} t_{i}\left|\operatorname{Im} \alpha_{i}\right| \\
& >\delta .
\end{aligned}
$$

This contradicts (1). Therefore $M=C$.

3. Function spaces generated by weakly compact convex subsets. Throughout this section, $S$ will denote a compact Hausdorff space and $X$ a (not necessarily closed) subspace of $C(S)$ with the sup norm. The mapping $\phi: S \rightarrow X^{*}$, defined by $\phi(s) x=x(s)$ for all $x \in X$ and for each $s \in S$, is a homeomorphism between $S$ and $\phi(S)$ with respect to the weak* topology of $X^{*}$. The convex set

$$
M=\left\{x^{*} \in X^{*} ; x^{*}(1)=1=\left\|x^{*}\right\|\right\}
$$

is the weak* closed convex hull of $\phi(S)$ and if $x^{*}$ is an extreme point of $M$, there is a point $s \in S$ such that $\phi(s)=x^{*}$. The set of extreme points of $M$ is called the Choquet boundary for $X$ (cf. [2] and [5]). By a peak point for $X$ we mean a point $s$ of $S$ such that there exists a function $x$ in $X$ with the property that $|x(s)|>|x(t)|$ for all $t \in S, t \neq s$.

THEOREM 3.1. Let $X$ be a separating subspace of $C(S)$ with $1 \in X$ and let $M=\left\{x^{*} \in X^{*} ; x^{*}(1)=1=\left\|x^{*}\right\|\right\}$. Then a linear functional $x^{*} \in M$ is a weak* absolute exposed point of $M$ if and only if there exists a peak point $s \in S$ for $X$ such that $x^{*}=\phi(s)$.

Proof. $\quad \Leftrightarrow$ If $x \in X$ exposes $x^{*}=\phi(s)$ absolutely, it follows easily that $x+1$ peaks at $s$.

$\Leftrightarrow$ Suppose that $s \in S$ is a peak point for $X$ and let $x$ be a function in $X$ which peaks at $s$. Then $\phi(s)$ is the only functional in $\phi(S)$ such that $\phi(s) x=1$. Let

$$
M_{\mathrm{x}}=\left\{x^{*} \in M ; x^{*}(x)=1\right\} .
$$


Since every extreme point of the weak* compact convex set $M_{\mathrm{X}}$ is an extreme point of $M$, hence in $\phi(S)$, we see that $M_{\mathrm{x}}=\{\phi(s)\}$ and therefore $\phi(s)$ is a weak* absolute exposed point of $M$.

The following example shows a weak* exposed point which is not a weak* absolute exposed point.

ExAmple 1. Let $S=\left\{\zeta=\xi+i \eta ; \xi^{4}+\eta^{4} \leqq 1\right\}$ and let $X \subset C(S)$ be the linear span of $x$ and 1 , where $x(\zeta)=\zeta$ for each $\zeta \in S$. Then the boundary of $S$ is the Choquet boundary for $X$ since $M$ is affinely homeomorphic to $S$. The points $\pm 1, \pm i$ are not weak* absolute exposed points of $M$ (i.e., they are not peak points for $X$ ), although they are weak* exposed points of $M$.

Our main theorem is an immediate consequence of Theorem 2.5 and Theorem 3.1.

THEOREM 3.2. Let $X$ be a separating subspace (not necessarily closed) of $C(S)$ such that $1 \in X$. If $X$ is generated by a weakly compact convex subset, then the peak points for $X$ are dense in the Choquest boundary for $X$.

Proof. The set $M=\left\{x^{*} \in X^{*} ; x^{*}(1)=1=\left\|x^{*}\right\|\right\}$ is the weak* closed convex hull of its weak* absolute exposed points. Since weak* absolute exposed points of $M$ are peak points for $X$ the theorem holds by Mil'man's theorem.

REMARK. The real case of Theorem 3.2 can be proved without the need of Theorem 2.5.

CoROLlary 3.3. Let $X$ be a separating subspace of $C(S)$ such that $1 \in X$. If there is a Banach space $Y$ generated by a weakly compact subset and a bounded linear operator from $Y$ onto $X$, then the peat points for $X$ are dense in the Choquet boundary for $X$.

Proof. Let $K$ be a weakly compact fundamental subset of $Y$. Then the continuous linear image of the closed convex hull of $K$ is a weakly compact convex fundamental subset of $X$.

ExAMPLE 2. Let $X$ be a separable, commutative, semi-simple Banach algebra with identity. $X$ is isomorphic to a subspace of $C(\mathscr{C})$ where $\mathscr{C}$ is the maximal ideal space of $X$. By the Corollary 3.3 peak points for $X$ are dense in the Choquet boundary for $X$. 
Example 3. Let $S$ be the Cantor set in $[0,1]$. Let

$$
X=\{f \in C(S) ; f \text { is a simple function }\} \text {. }
$$

$X$ is clearly a separating subalgebra of $C(S)$ with $1 \in X$ but $X$ contains no peaking function and hence there is no peak point for $X$ in $S$. Since $X$ is separable, it contains a weakly compact fundamental subset, however it contains no weakly compact convex fundamental subset by Theorem 3.2.

The author would like to express his sincere gratitude to Professor P. C. Curtis, Jr., the author's thesis advisor, for valuable advice and consultation.

\section{BIBLIOGRAPHY}

1. D. Amir and J. Lindenstrauss, The structure of weakly compact subsets in Banach spaces, Ann. of Math. 88 (1968), 35-46.

2. E. Bishop and $\mathrm{K}$. deLeeuw, The representation of linear functionals by measures on sets of extreme points, Ann. Inst. Fourier (Grenoble) 9 (1959), 305-331.

3. M. M. Day, Normed Linear Spaces, Springer-Verlag, 1962.

4. V. L. Klee, Jr., Some new results on smoothness and rotundity in normed linear spaces, Math. Ann. 139 (1959), 51-63.

5. R. Phelps, Lectures on Choquet's Theorem, Van Nostrand, 1966.

Received November 7, 1969. This is a part of the author's doctoral dissertation submitted to UCLA in 1969.

State University of New York, Albany 


\section{PACIFIC JOURNAL OF MATHEMATICS}

\section{EDITORS}

\author{
H. SAMELSON \\ Stanford University \\ Stanford, California 94305 \\ Richard Pierce \\ University of Washington \\ Seattle, Washington 98105
}

\author{
J. DugundJI \\ Department of Mathematics \\ University of Southern California \\ Los Angeles, California 90007 \\ RICHARD ARENS \\ University of California \\ Los Angeles, California 9.0024
}

\section{ASSOCIATE EDITORS}

\begin{tabular}{|c|c|}
\hline E. F. BECKENBACH & K. YoshidA \\
\hline \multicolumn{2}{|c|}{ SUPPORTING INSTITUTIONS } \\
\hline UNIVERSITY OF BRITISH COLUMBIA & STANFORD UNIVERSITY \\
\hline CALIFORNIA INSTITUTE OF TECHNOLOGY & UNIVERSITY OF TOKYO \\
\hline UNIVERSITY OF CALIFORNIA & UNIVERSITY OF UTAH \\
\hline MONTANA STATE UNIVERSITY & WASHINGTON STATE UNIVERSITY \\
\hline UNIVERSITY OF NEVADA & UNIVERSITY OF WASHINGTON \\
\hline NEW MEXICO STATE UNIVERSITY & $* \quad * \quad *$ \\
\hline OREGON STATE UNIVERSITY & AMERICAN MATHEMATICAL SOCIETY \\
\hline UNIVERSITY OF OREGON & CHEVRON RESEARCH CORPORATION \\
\hline OSAKA UNIVERSITY & TRW SYSTEMS \\
\hline UNIVERSITY OF SOUTHERN CALIFORNIA & NAVAL WEAPONS CENTER \\
\hline
\end{tabular}

The Supporting Institutions listed above contribute to the cost of publication of this Journal, but they are not owners or publishers and have no responsibility for its content or policies.

Mathematical papers intended for publication in the Pacific Journal of Mathematics should be in typed form or offset-reproduced, (not dittoed), double spaced with large margins. Underline Greek letters in red, German in green, and script in blue. The first paragraph or two must be capable of being used separately as a synopsis of the entire paper. The editorial "we" must not be used in the synopsis, and items of the bibliography should not be cited there unless absolutely necessary, in which case they must be identified by author and Journal, rather than by item number. Manuscripts, in duplicate if possible, may be sent to any one of the four editors. Please classify according to the scheme of Math. Rev. Index to Vol. 39. All other communications to the editors should be addressed to the managing editor, Richard Arens, University of California, Los Angeles, California, 90024.

50 reprints are provided free for each article; additional copies may be obtained at cost in multiples of 50 .

The Pacific Journal of Mathematics is published monthly. Effective with Volume 16 the price per volume (3 numbers) is $\$ 8.00$; single issues, $\$ 3.00$. Special price for current issues to individual faculty members of supporting institutions and to individual members of the American Mathematical Society: $\$ 4.00$ per volume; single issues $\$ 1.50$. Back numbers are available.

Subscriptions, orders for back numbers, and changes of address should be sent to Pacific Journal of Mathematics, 103 Highland Boulevard, Berkeley, California, 94708.

PUBLISHED BY PACIFIC JOURNAL OF MATHEMATICS, A NON-PROFIT CORPORATION

Printed at Kokusai Bunken Insatsusha (Internatıonal Academic Printing Co., Ltd.), 7-17, Fujimi 2-chome, Chiyoda-ku, Tokyo, Japan. 


\section{Pacific Journal of Mathematics}

\section{Vol. 35, No. $3 \quad$ November, 1970}

John D. Arrison and Michael Rich, On nearly commutative degree one algebras . . . 533

Bruce Alan Barnes, Algebras with minimal left ideals which are Hilbert spaces . . . . 537

Robert F. Brown, An elementary proof of the uniqueness of the fixed point index . . . 549

Ronn L. Carpenter, Principal ideals in F-algebras .................... 559

Chen Chung Chang and Yiannis (John) Nicolas Moschovakis, The Suslin-Kleene

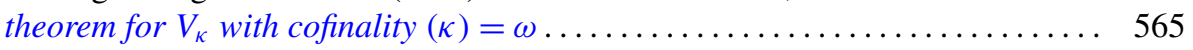

Theodore Seio Chihara, The derived set of the spectrum of a distribution

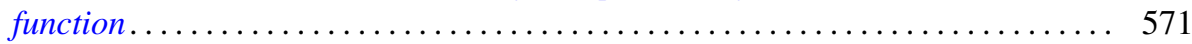

Tae Geun Cho, On the Choquet boundary for a nonclosed subspace of $C(S) \ldots \ldots \quad 575$

Richard Brian Darst, The Lebesgue decomposition, Radon-Nikodym derivative,

conditional expectation, and martingale convergence for lattices of sets .......

David E. Fields, Dimension theory in power series rings . . . . . . . . . . . .

Michael Lawrence Fredman, Congruence formulas obtained by counting

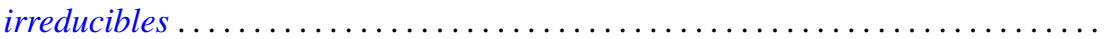

John Eric Gilbert, On the ideal structure of some algebras of analytic functions.....

G. Goss and Giovanni Viglino, Some topological properties weaker than

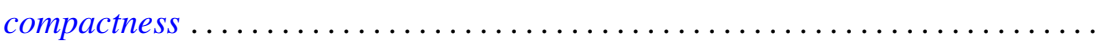

581

601

625

George Grätzer and J. Sichler, On the endomorphism semigroup (and category) of

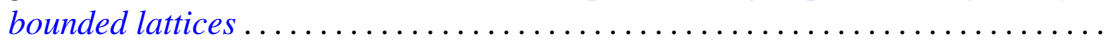

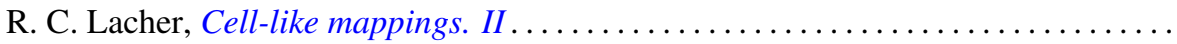

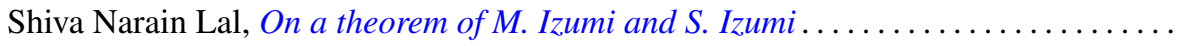

661

Howard Barrow Lambert, Differential mappings on a vector space ...............

Richard G. Levin and Takayuki Tamura, Notes on commutative power joined

semigroups.

Robert Edward Lewand and Kevin Mor McCrimmon, Macdonald's theorem for quadratic Jordan algebras.

J. A. Marti, On some types of completeness in topological vector spaces ....

Walter J. Meyer, Characterization of the Steiner point

717

Saad H. Mohamed, Rings whose homomorphic images are $q$-rings ...

727

Thomas V. O'Brien and William Lawrence Reddy, Each compact orientable surface

of positive genus admits an expansive homeomorphism ...

737

Robert James Plemmons and M. T. West, On the semigroup of binary relations...

743

Calvin R. Putnam, Unbounded inverses of hyponormal operator . .

755

William T. Reid, Some remarks on special disconjugacy criteria for differential

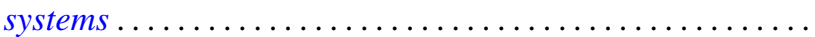

C. Ambrose Rogers, The convex generation of convex Borel sets in euclidean

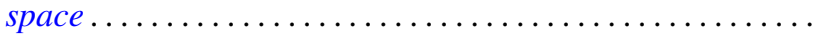

S. Saran, A general theorem for bilinear generating functions .

S. W. Smith, Cone relationships of biorthogonal systems ......

Wolmer Vasconcelos, On commutative endomorphism rings ....

795

Vernon Emil Zander, Products of finitely additive set functions from Orlicz

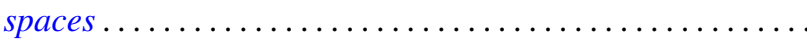

G. Sankaranarayanan and C. Suyambulingom, Correction to: "Some renewal

theorems concerning a sequence of correlated random variables" .

Joseph Zaks, Correction to: "Trivially extending decompositions of $E^{n}$ ”....... 805

Dong Hoon Lee, Correction to: "The adjoint group of Lie groups" ............ 805

James Edward Ward, Correction to: "Two-groups and Jordan algebras". 